\title{
LOS DIOSES DE LA ILÍADA (II)
}

\author{
Bartolomé Segura Ramos \\ Universidad de Sevilla \\ bsegura@us.es
}

\section{THE GODS IN THE ILIAD (II)}

RESUMEN: Continuación del artículo incluido con el mismo título en el número 44 de esta revista.

PALABRAS CLAVE: Dioses, naturaleza, seres humanos, carácter, interrelación.
ABSTRACT: This is a continuation of the previous paper included with the same title in this journal.

KEYWORDS: Gods, Nature, Human Beings, Character, Interrelation.

RECIBIDO: 13.05.2013. ACEPTADO: 13.06.2013

\section{Palas Atenea}

"Acompañante y guía en la Odisea, en la Ilíada es sobre todo "luchadora" (Erbse 1986: 126).

Atenea actúa en el poema de consuno con Hera, con la que jamás tiene una fricción. Ya al comienzo del poema, Atenea obedece por dos veces los encargos que aquella le hace. Así, en I 194-218, en el momento crítico en que Aquiles duda si matar a Agamenón, Hera envía de inmediato a Atenea para que calme al héroe y le haga desistir de sus intenciones. Agarrándole por la rubia cabellera, le impide sacar la espada, Aquiles la reconoce y Atenea le revela que ha venido por orden de Hera para calmar su impulso, "porque Zeus os ama por igual a los dos" (209). Aquiles, obediente, hace caso a la diosa. Igualmente, en II 156-181, Atenea desciende al campo de batalla para impedir que los aqueos regresen a las naves y vuelvan a la patria. Atenea cumple la misión, encargando la tarea de detener a los griegos a Ulises, que ejecuta el encargo hablando con los diferentes jefes y con la 
tropa. Más adelante (IV 64-80), a propuesta de Hera (64-5: "manda que Atenea vaya a la terrible lucha de troyanos y aqueos"), Zeus encarga a la diosa guerrera (70) que meta cizaña entre ellos para que el combate (tras el duelo fracasado entre París y Menelao) se reanude y sean los troyanos quienes rompan los juramentos. Oído el encargo, Atenea, de mil amores, desciende del Olimpo, "como un astro prodigioso" (75-6), que asusta a todos, y busca a Pándaro.

Atenea también está presta a obedecer a Zeus, siempre que se trate de favorecer a los aqueos. Así, cuando los aqueos no son capaces de defender el cadáver de Patroclo, Zeus (que ahora ha cambiado de idea, y vuelve a ayudar a los griegos) envía a la diosa para que exhorte a los aqueos en general y a Menelao en particular. Su descenso asemeja un arcoíris, otro prodigio como el de la estrella precedente, y bajo la apariencia del viejo maestro de Aquiles, Fénix, interpela al Atrida. Este, que no reconoce a la diosa, pide ayuda a la misma, y Atenea se regocija, porque ha rezado a ella la primera. Entonces, infunde vigor en los hombros y rodillas del héroe y en su pecho "el valor de la mosca" (570). En el libro XIX, el Pelida llora desconsoladamente a su amigo Patroclo, caído en combate; todo el mundo acompaña su llanto. Compadecido, Zeus ordena a Atenea que acuda al lado de Aquiles y le suministre néctar y ambrosía, para que el hambre no acabe con él (341-51). La diosa obedece y desciende a cumplir con su misión "como un ave marina de sonoro graznido" (350).

Naturalmente, nadie va a auxiliar como ella a sus queridos héroes aqueos. Ya en II 279-81, cuando Ulises va a dirigirse a la asamblea para retener a la tropa y continuar el combate, Atenea, con el aspecto de un heraldo, manda al ejército guardar silencio. Cuando el mismo Ulises vacila entre perseguir a Sarpedón, hijo de Zeus tronador, o continuar matando troyanos, Atenea "le dirigió la voluntad a lo segundo" (V 676). Preguntado Diomedes por quién elige por compañero para que le acompañe en la expedición nocturna para espiar a los troyanos, el héroe argivo contesta que a Ulises "al que ama Palas Atenea" (X 245). A punto de partir para su misión, la diosa les envía (a Ulises y Diomedes) una garza real, que les sale por la derecha. Contento con el agüero, Ulises reza a Atenea, pidiéndole que le permita regresar a las naves, tras llevar a cabo una gran hazaña (X 274-82). A la vuelta de la tarea encomendada, Néstor alaba a los héroes, y finaliza su discurso, aseverando que "a ambos os ama Zeus y Atenea, la ojizarca, la chica de Zeus, portador de la égida" (X 553). Soco dispara a Ulises y el dardo atraviesa la coraza y araña la piel, pero Atenea "no dejó que la lanza llegase a las entrañas del hombre" (XI 436-8). En la carrera atlética, Ulises se enfrenta a Ayante, hijo de Oileo y a Antíloco, hijo de Néstor. Hacia el final de la misma, el héroe de Ítaca reza a la diosa, rogándole que fortalezca sus piernas (XXIII 770); y Ulises ganó la carrera.

Paris se disculpa ante Hélena por no haber ganado el duelo con Menelao, "puesto que Menelao ha ganado con la ayuda de Atenea" (III 439). Pándaro, hijo de Licaón, siguiendo la recomendación artera de Palas Atenea, dispara una flecha a Menelao, que llega a herir a este. Mas no le alcanzó de muerte, porque Atenea, 
“poniéndose delante, lo resguardó del disparo, apartándola del cuerpo, como una madre aleja a la mosca que molesta al niño que duerme" (IV 128-131).

También a Tideo, padre de Diomedes, había protegido Palas Atenea, como leemos en IV 390, donde se dice que "era su gran protectora".

En los dos primeros versos del libro quinto, la diosa infunde a Diomedes vigor y valentía. Pándaro se enfrenta al héroe argivo, le dispara una flecha y lo hiere; Esténelo, el escudero de Diomedes, le saca la flecha. Diomedes reza a Atenea (V 115-120), recordándole que ella había protegido también a su padre, Tideo. Atenea lo escucha y hace ágiles sus miembros, brazos y piernas, y lo interpela (124-32), revelándole que le ha inspirado "el vigor de su padre", y le recomienda que, dejando a un lado a los demás dioses, persiga y hiera a Afrodita. Más adelante, es Diomedes el que dispara a Pándaro. En esta ocasión, la diosa dirige hacia la nariz y boca del rival el dardo, que le corta la lengua. Pándaro pierde la vida (V 290-6). En un largo pasaje, al que ya hemos aludido más arriba (V 713 859), Palas Atenea prepara el carro para descender al campo de batalla con Hera. Ambas se acercan a los aqueos que estaban en torno de Diomedes (781), al que la diosa se acerca (793). El héroe está curándose la herida causada por Pándaro. Agarrada al yugo del caballo, Atenea habla al héroe (800-813), riñéndole porque no se parece a su padre, cuyas hazañas enumera; el héroe le responde que ella le ha prohibido atacar a los dioses; la contestación de ella es ordenarle atacar a Ares (826-34). La diosa monta en el pescante del carro, tras apartar de él a Esténelo, y, oculta bajo el casco de Hades para que no la reconozca Ares, ambos, la diosa y el héroe, avanzan contra él. Cuando el dios ataca a Diomedes (859-62), Palas Atenea desvía su lanza (854), y, por el contrario, cuando ataca Diomedes, dirige la lanza de este y hiere al dios en el ijar. Persiguiendo a Dolón, Diomedes recibe "el vigor" que Atenea le propina (X 366), para que ningún aqueo alcanzara al espía troyano antes que el héroe argivo. Luego, mientras duda si llevarse el carro de Reso o seguir matando tracios, la diosa le dirige unas palabras, recordándole que debe volver, no sea que otro dios despierte a los troyanos (X 507-12). En la carrera de carros, Atenea neutraliza la ventaja que Apolo ha dado a Eumelo; primero, devuelve la tralla a Diomedes, y a continuación, irritada contra el otro, le rompe el yugo (XXIII 388-92), de manera que Diomedes sobrepasa a Eumelo y todos los demás, porque Atenea "puso vigor en los caballos y concedió a él la gloria" (XXIII 399-400).

El amor y cuidado de Atenea por Aquiles son evidentes. Cuando Iris pide al héroe que se muestre a los troyanos para que estos liberen el cadáver de Patroclo, la diosa Atenea pone en los hombros del héroe la égida y en torno a su cabeza una nube de oro (XVIII 203-6). De esta guisa, el Pelida ahuyenta al enemigo, y los aqueos recuperan el cuerpo de su camarada. En el enfrentamiento de Aquiles con Héctor, la diosa desvía la lanza de este dirigida al héroe tesalio de un soplo (XX 438-40). Abrumado por su lucha con el río Escamandro, el Eácida recibe la ayuda de Atenea (y de Posidón), que lo reconforta con sus palabras (XXI 284-6); 
a partir de ese momento, Aquiles puede combatir con el río, "pues Atenea le inspiró una gran fuerza” (XXI 304).

Entre los dioses, a quien con más saña persigue la diosa es al dios tracio de la guerra, Ares. En V 29-35, Atenea aborda al dios en mitad de la refriega entre Diomedes y los troyanos; tras insultarle, le propone llegar a un acuerdo: dejar ellos a ambos bandos, evitando la cólera de Zeus, para que alcance la victoria el que este decida. De este modo, saca al dios de la batalla, lo sienta cabe el Escamandro, y los dánaos derrotan a los troyanos. Ya hemos visto cómo, subida al carro de Diomedes, Atenea ha dirigido la lanza de este contra Ares, causándole una herida (V 855 ss.). Al final del canto, Atenea (con Hera), regresa "a la casa del gran Zeus, después de poner fuera de combate a Ares, perdición de los mortales" (V 907-9).

También hemos visto ya cómo la diosa engaña a Pándaro, hijo de Licaón, proponiéndole que dispare a Menelao para causarle la muerte, cuando en realidad la intención de la gran enemiga de los troyanos es que estos rompan los juramentos (IV 86-104). Ahí, bajo la apariencia de un hombre, Laódoco, hijo de Anténor, la diosa busca y encuentra a Pándaro, al que engatusa diciéndole que Paris le recompensará, si ve a Menelao "subir a la pira fúnebre", haciéndole muchos regalos; y le sugiere que rece a Apolo, al que debe prometer una hecatombe de corderos cuando vuelva a su ciudad en Zelea. Ya sabemos también que Pándaro no dará muerte a Menelao, y que en cambio perecerá a manos de Diomedes en el canto siguiente. Más amargo, si cabe, es el engaño que Atenea hace a Héctor. Pero antes de que llegue esa hora, el poeta nos muestra a un Héctor confiado, porque Zeus lo estima y glorifica, "ya que iba a vivir poco, porque Palas Atenea ya empujaba contra él el día fatal bajo la violencia del Pelida" (XV 612-4). De la misma manera, de las propuestas de Polidamante y Héctor en el libro XVIII, Atenea favorece el plan insensato del segundo, que es el que aceptan los troyanos, "a los que Palas Atenea había quitado el entendimiento" (311). Por fin, en el enfrentamiento decisivo entre Héctor y Aquiles, toda vez que el primero huía y no presentaba batalla, cuando ya Zeus había pesado los destinos y el de Héctor se inclinaba al Hades, y lo abandonaba Apolo (XXII 209-13), Palas Atenea resuelve acercarse al Pelida para decirle que ya ha llegado el momento de acabar con Héctor, al que no podrá ayudar Apolo. "Quédate aquí" -le dice a Aquiles-, "que yo saldré a su encuentro y lo convencerá de que luche frente a ti” (222-3). Y en efecto, bajo la apariencia del hermano de Héctor, Deífobo, la diosa aborda al héroe troyano (229 ss.), con el que mantiene una conversación, en la que lo convence para que plante cara a Aquiles. Héctor se traga el anzuelo, y agradece a su hermano que se haya atrevido a salir de las murallas, dentro de las cuales quedan los demás. Le responde el pseudo-Deífobo que los padres le pedían que no saliera, porque todo el mundo teme al Pelida; pero a él le dolía el alma de pena. Acto seguido, la diosa le propone que ambos se enfrenten a Aquiles, "tanto si este se ha de llevar los despojos a las naves, como si ha de caer bajo la lanza de Héctor" (239-46). A continuación, nos dice el poeta (247): “Tras hablar así, con perfidia Atenea se puso 
a guiarlo". Como es notorio, Héctor perecerá ante Aquiles, habiendo averiguado instantes antes el engaño. Versos más adelante, Andrómaca ignora aún la muerte de su esposo, "que, muy lejos del baño había abatido a manos de Aquiles Atenea, de ojos zarcos" (XXII 445-6).

Si bien, como hemos comprobado, Palas Atenea es una diosa bélica, que odia a los troyanos y protege a los aqueos, hay en la Ilíada también algunos vestigios de lo que la diosa representará, quizá más habitualmente, en el panteón griego, una diosa, pues, que podríamos tildar de "civil", por cuanto, de un lado, asume el papel de "protectora de la ciudad", y, del otro, simboliza a la patrona de las artes artesanales y otras labores. En calidad de lo primero, encontramos a la diosa en el libro VI, en que, a petición de Héctor, Hécuba y demás ancianas troyanas van a acudir al templo de la diosa en la acrópolis (88) para depositar en sus rodillas (92) un peplo, el mejor que la reina madre troyana guarda en su arca. Llegadas al templo, las matronas alzan las manos a la diosa, profiriendo el grito de lamento ritual (301). Entonces, Teanó, "la sacerdotisa de la diosa" (300), reza a Atenea, "protectora de la ciudad" (305), pidiendo que rompa la lanza de Diomedes, a cambio de lo cual las troyanas le ofrecen sacrificar doce vacas en su templo (308), templo al que Héctor supone que ha marchado también Andrómaca cuando visita la casa y no encuentra a su mujer en ella (379 y 384).

Como "patrona de las artes" hallamos a la diosa, por ejemplo, en V 59-63, donde leemos que "Atenea amaba sobremanera a Fereclo, hijo de Armónida, el carpintero" (61). El tal Fereclo había construido las naves de Paris y "sabía hacer con sus manos toda clase de primores" (60). Cuando, en el libro IX, Aquiles replica irritado que no aceptará casarse con la hija de Agamenón, agrega que no lo hará "aunque rivalizara en belleza con Afrodita y con Atenea en realizar labores" (389-90). Para conquistar a Zeus, Hera se viste "un vestido divinal que había alisado Atenea" (XIV 178-9). Por último, el carpintero que fabrica la quilla de un barco con toda perfección, es un experto que "conoce bien su arte gracias al adiestramiento de Atenea" (XV 410-12).

Apolo

"Es la figura más significativa de todos los dioses homéricos; entre los griegos florecería más tarde" (Erbse 1986: 188).

Esta divinidad es la tercera que aparece en el poema, detrás de Zeus (I 5), su padre (I 9 y 21) y de su propia madre, Letó (I 9). Inmediatamente después, Crises hace acto de presencia, portando las ínfulas del dios (I 14), y es denominado Febo Apolo, por primera vez, en I 43 (cf. también, sin salirnos de este libro, 64, 72, 182, 373). Respondiendo al ruego de Crises, el dios de las flechas ha provocado una peste en el ejército aqueo, que está causando muchas muertes. La situación dura ya nueve días; entonces, Calcante, a ruegos de Aquiles, va a dar su vaticinio, 
explicando la razón de la "cólera de Apolo" (I 75). Según él, Apolo exige que se devuelva Criseida a su padre y que se realice una sagrada hecatombe en Crisa; de momento, en el mismo campamento aqueo y a la orilla del mar, hacen una hecatombe de toros y cabras (I 315), sin perjuicio de la que realizará Ulises con sus marineros en la propia isla de Crisa, como se había ordenado (I 438). Al regresar, el dios favorece la navegación de los marineros capitaneados por Ulises, enviando un viento favorable (I 479). El libro primero termina con una fiesta de los dioses en el cielo, en la que Apolo toca la forminge (I 603).

Junto a Zeus y Palas Atenea, Apolo es invocado al inicio de una plegaria ("ojalá que el padre Zeus, y Atenea, y Apolo"). La primera vez acontece en II 371 (ora Agamenón). Otros ejemplos son: IV 288 (otra vez, Agamenón); VII 132 (Néstor); XVI 97 (Aquiles). Al finalizar el catálogo de las naves griegas, Homero afirma que las mejoras yeguas del ejército eran las de Eumelo (que ya hemos visto corriendo en la carrera de carros, en libro XXIII), "rápidas como los pájaros" (II 764). Pues bien, fue Apolo quien las había criado en Perea (766).

A diferencia de Palas Atenea, Apolo es defensor de los troyanos (aun cuando en el libro primero no se pone de manifiesto este rasgo). De ahí que, en adelante, asistamos a las continuas ayudas que el dios presta a los habitantes de Ilion. Así, para empezar, como portador del arco que es Apolo, también a Pándaro, hijo de Licaón y habitante del Ida, se nos dice en el catálogo troyano que le había dado el arco (827). Por eso es por lo que Atenea, cuando sugiere a Pándaro que dispare contra Menelao, le recomienda que "haga a Apolo, ilustre por su arco, una hecatombe de corderos primogénitos" (IV 101-2=119-20). A finales del presente libro, los aqueos se están imponiendo en el combate a Héctor y sus troyanos. Apolo, observando esta circunstancia desde Pérgamo, la acrópolis de Ilion, se irrita y arenga a los troyanos contra los aqueos, haciéndoles ver que éstos no son de piedra ni de hierro (507-14).

Afrodita protege a su hijo Eneas, que ha sido herido por Diomedes; herida la diosa a su vez, es Apolo quien recoge entre sus brazos al héroe troyano, envolviéndolo en una nube azulenca (V 344-5). Más adelante, Diomedes persiste en perseguir a Eneas, a pesar de saber que lo protege Apolo. Este interpone su escudo entre los dos combatientes, hasta que, harto del descaro de Diomedes, lo conmina a retroceder, porque "dioses y hombres no son de la misma etnia" (V 440-2). Diomedes se aparta un poco, y Apolo traslada a Eneas a la acrópolis, donde lo deja al cuidado de su madre Letó y su hermana Ártemis; él, por su parte, fabrica un muñeco similar a Eneas, en torno al cual se pelean griegos y troyanos. Entonces, el dios interpela a Ares, al que pide que saque de la batalla a Diomedes, que ha herido a Afrodita y le ha amenazado a él mismo. Tras hablar así, y mientras Ares marcha a cumplir su mandato, Apolo toma asiento en la acrópolis troyana (443-60).

Aqueos y troyanos luchan a muerte a principios del libro VII. Atenea baja del Olimpo a la sagrada Ilion para ayudar a sus griegos. Apolo la divisa y a su vez 
desciende de Pérgamo para salirle al encuentro junto a la encina, "pues quería la victoria para los troyanos" (VII 20-21). Luego, aborda a Atenea, preguntándole (retóricamente) la razón de su venida; le echa en cara su falta de piedad para con los troyanos y le propone detener el combate hasta el día siguiente, ya que ella con otras diosas (en realidad, se trata solo de otra, a saber, Hera) anhelan la destrucción de Troya (24-32). A la pregunta de la diosa sobre el modo de poner fin a la lucha ese día, Apolo responde que lo mejor es que Héctor rete a un griego a duelo singular, para lo que es prioritario infundir al héroe troyano "un fuerte vigor" (33-42). A la hora de proponer el duelo, Héctor afirma (VII 81-3) que "si Apolo me da la victoria, colgaré en su templo las armas del enemigo". Apolo, al contrario de Atenea, apoya incesantemente a Héctor; en VII 272 "a Héctor lo puso de pie de inmediato Apolo" (en XI 353 vemos cómo el yelmo de Apolo salva de la muerte al héroe, detalle que le recuerda, resentido, Diomedes, diez versos más abajo). En VIII 311, Teucro dispara al héroe troyano y falla, gracias a Apolo. Tal es la protección que el dios dispensa al héroe troyano que el propio Zeus le encarga su defensa (XV 55 y 59: "que Febo Apolo impulse al combate a Héctor"), encargo que se repite poco más adelante (220-262; una vez que se haya marchado del campo de batalla Posidón, "sea preocupación tuya, flechador, el ilustre Héctor" -231-). Y en efecto, el dios desciende, como el gavilán, en busca de Héctor, al que revela la atención que le merece (el propio Cronión lo ha enviado como protector del héroe), y lo llena de vigor (262). Versos después, Apolo, provisto de la égida, guía a los troyanos (306-11), ahuyentando a los aqueos (318-27: "así huían los aqueos acobardados, pues Apolo les había infundido la huída y a los troyanos y a Héctor les otorgaba la gloria"). Luego, allana el camino de los troyanos, arrasando parcialmente el muro; en 521 salva a Polidamante, el asesor del caudillo troyano.

Este interés del dios por la ciudad de Troya es reconocido incluso por Aquiles, quien en XVI 94 revela a Patroclo que "Apolo ama mucho a los troyanos". $\mathrm{Al}$ igual que Atenea infundía fuerza continuamente a Diomedes, Apolo hace lo propio con los troyanos, y no solo con Héctor. Así, por ejemplo, en XVI 513-29, Glauco, el licio, herido, reza al dios que lo cure y el dios lo escucha, y le confiere energía. Igualmente, dado que Sarpedón licio, igualmente y primo de Glauco, cae en combate, Apolo es el encargado de recoger su cadáver, para entregarlo a Sueño y Muerte (XVI 667-80). En los versos siguientes, el dios impide que el camarada de Aquiles, Patroclo, tome Troya, y acto seguido, bajo la apariencia del joven Asio, Apolo exhorta a Héctor a perseguir a Patroclo y sus caballos, y repite el poeta (729-30): “Otorgaba la gloria a los troyanos y a Héctor". En la muerte de Patroclo, intervienen varios actores; el primero es Apolo, que le quita el caso y le afloja la coraza (788-804); cuando el compañero de Aquiles está a las puertas de la muerte, recuerda a Héctor que debe su victoria a (Zeus) y Apolo, que le despojaron de las armas (844-6). En la muerte de Patroclo, interviene además, Euforbo Pantoida, cuyas armas pretende llevarse Menelao. Pues bien, Apolo lo impide, advirtiéndoselo a Héctor (XVII 70-81); y una vez más el dios "inspira divino miedo a los aqueos" (XVII 118). Luego, en los versos del mismo canto, 322-34, 
el dios, con el aspecto del heraldo Perifante, exhorta a Eneas para que entre él, Héctor y los demás, eviten que los aqueos tomen Ilion, y en XVII 582-90, bajo la apariencia de Fénope, advierte a Héctor de que Menelao ha matado a su fiel camarada Podés, cuya muerte produce enorme congoja al héroe. También Tetis, en su narración de los avatares que le llevan a pedir unas armas nuevas para su hijo, cuenta a Hefesto que Apolo impidió a Patroclo tomar Troya, dando, así, gloria a Héctor (XVIII 454-6).

En el libro XX, Apolo, bajo la apariencia de Licaón, hijo de Príamo, invita a Eneas a enfrentarse a Aquiles. Eneas lo rehúye, porque el héroe tesalio lo había perseguido ya en el monte Ida, pero el dios le recuerda que es hijo de Afrodita, mientras que Aquiles es solo hijo de Tetis; Apolo le inspira poder y se enfrenta a su enemigo (68-138). Más adelante, este enfrentamiento es echado en cara al dios por Posidón (XX 295). En los versos 375-8, por el contrario, el dios desaconseja a Héctor enfrentarse a Aquiles, y en los versos 443-50, lo salva de sus garras. El héroe tesalio, a su vez, recuerda a Zeus (XXI 278) que morirá por los disparos de Apolo.

En la teomaquia, Posidón propone a Apolo que pelee con él (XXI 436), a lo que Apolo se opone (462-7), gesto que su hermana, Ártemis, le afea (472-8). Luego, preocupado por el destino de Troya, el dios penetra en la ciudad, temeroso de que los aqueos la destruyan ese mismo día (515-7), razón por la que se opone a Aquiles (538-9), y empuja a Agénor, hijo de Anténor, para que detenga al héroe (544-5); el dios salva mediante una nube a Agénor (516-8), y engaña al Pelida, adoptando el aspecto de Agénor (600-5). Ambos, Aquiles y Apolo, con la figura de Agénor, conversan, antes de que el Eácida prosiga su marcha hacia Troya (XXII 7-20). Y ya se aproxima el final de Héctor, "domador de caballos". Apolo, que tantas veces lo ha protegido, solo podrá ayudarle ya una vez más (XXII 203-4). Zeus pesa los destinos de ambos héroes, el argivo y el troyano, $\mathrm{y}$, dado que el de Héctor desciende al Hades, Apolo ha de abandonarlo para siempre (212-3): Atenea se jactará ante el Pelida que, aunque Apolo se arrodille ante Zeus, Héctor ya no se les podrá escapar (219-21). En XXII 359-60, Héctor, ya moribundo, profetiza a su enemigo su futura muerte a manos de Apolo en las puertas Esceas.

Además de Apolo, también Afrodita vela, en cuanto puede, por Héctor, es decir, por su cadáver, ya. Para completar su labor, Apolo extiende una nube azulada "desde el cielo a la llanura" para protegerlo de los rayos del sol (XXIII 18891). También en la carrera de carros, interviene Apolo, en contra, en este caso, de Diomedes (XXIII 383-4) y, más adelante (872-3), en el tiro al blanco, favorece a Meríones (escudero de Idomeneo, el caudillo cretense) frente a Teucro (que es aqueo “puro"). Y continúa protegiendo el cadáver de Héctor, ahora del daño que podría causarle Aquiles al arrastrarlo con el carro (XXIV 18-21), interponiendo su égida. Por último, en los versos 32-76, el dios hace un alegato para que se tenga consideración con el cuerpo del troyano. Pese a la oposición implacable de Hera, Zeus resuelve que el cadáver de Héctor sea rescatado de manos de Aquiles por su padre, Príamo, soberano de Troya. 
ARES

"El poeta representa en Ares, en su barbarie y en su derrota, la sinrazón de los troyanos y su fracaso. El poeta lo caracteriza como necio, irresponsable, ligero de cascos, y poco de fiar. El dios parece remontarse al milenio II a. C." (Erbse 1986: 154).

Aunque Ares, sorprendentemente, como veremos, defiende a los troyanos, los aqueos son calificados, rutinariamente, como "escuderos de Ares" (la primera vez en II 110; y también en VI 67; VII 382; o si no, algunos de aquellos, como los dos Ayantes en VIII 79 y X 228; o, por último, Ulises y Diomedes en XIX 47). Muchos héroes reciben la denominación de "retoño de Ares" (II 540 = Elefénor; II 663 y XX 238 = Licimnio; II 704 = Podarces; XII 188, XXIII 841 y XXIV 745 = Leonteo; XXIV $474=$ Alcimedonte). Los epítetos más habituales que le acompañan son: "impetuoso" (V 30; VIII 215; XIII 295, 328, 528; XV 127, 142; XVI 784; XVII 72, 536; XXI 406; XXIV 498); “poderoso" (XIII 444 y 521; XV 112; XVI 613; XVII 529); “perdición de los hombres” (V 31; VIII 349; XI 295; XII 130; XIII 298 y 802; XX 46; XXI 422); en menor cuantía, "que lleva escudo de piel" (V 288; XX 78); "broncíneo" (VII 146; XVI 543); "manchado de crímenes" (V 31; XXI 402); etc.

La presencia de Ares se detecta, esencialmente, en el libro V; parcialmente, en la teomaquia de XX-XXI, e incidentalmente en XV 128-141. Al margen de esas actuaciones del dios, su nombre simboliza fundamentalmente la guerra, de la que su nombre es metonimia. Amén de usos en que se realza el porte de un héroe comparándolo a Ares (por ejemplo, Agamenón, en II 479, armado, posee "la cintura de Ares"). El dios tiene dos hijos, Ascálafo (que muere) e Iálmeno (II 512 y IX 82). Y Éride o la Discordia es su hermana (IV 440).

Ares es la contrafigura de Palas Atenea (la misión de los dos es, en boca de Zeus (V 430) "las hazañas bélicas", en contraposición a Afrodita, cuya misión son "las hazañas del matrimonio"). Así es como en IV 439 vemos que ambos conducen, respectivamente, a los troyanos, el uno y a los aqueos, la otra. En el libro V, Atenea empieza por sacar del combate a Ares (V 30-35). Más adelante, Afrodita, herida por Diomedes a instancias de Atenea, busca a su hermano, Ares, al que halla con la lanza y sus rápidos caballos apoyados en una nube (355-63); la diosa le pide que le preste el carro, y el dios se lo entrega. Dione, madre de Afrodita en la Ilíada, trata de consolar a su hija, contándole diversas anécdotas, entre ellas, la de la prisión del dios a manos de los gigantes Oto y Efialtes, los Aloidas. Como réplica a la actuación de Atenea, quien ha echado fuera del campo de batalla a Ares, Apolo ahora pide a Ares que saque del combate al héroe que más protege Atenea, Diomedes, que, como ya hemos visto, ha herido a Afrodita y hecho ademán de atacarle a él mismo. Obediente, Ares, bajo la apariencia de Acamante, arenga a los troyanos, recordándoles que ha sido herido Eneas (454-69), al que, tras cubrir con una noche el campo de batalla, y dado que Apolo se lo ha llevado al templo 
de la acrópolis para defenderlo de Diomedes, el dios saca del santuario (506-13). A partir de los versos 592 ss., Ares dirige las filas troyanas, portando su enorme lanza, deambulando ora delante de Héctor, ora detrás; Diomedes, desesperado, revela a sus compañeros que Ares acompaña a Héctor bajo aspecto humano, lo que repite más abajo, verso 824; por ello, los aqueos retroceden, al saber que Ares se halla entre los troyanos (699-702). Ante tal panorama, intervienen las diosas, Hera y Atenea, que piden a Zeus permiso para bajar a la llanura troyana ( 717 ss.). Ya sabemos cómo acaba la situación: a instancias de Atenea, Diomedes, con ayuda de la diosa, hiere a Ares, que grita salvajemente y se aleja del combate (841-904).

No volvemos a tener noticias del dios hasta diez cantos después, es decir, el canto XV. Ahí (128-141), Ares, al enterarse por Hera de que su hijo Ascálafo ha muerto, se golpea entristecido los muslos (es una señal de dolor, que se repite en otros lugares del poema) y se levanta presto a armarse y bajar al campo de bata1la. Palas Atenea lo retiene y le obliga a dejar las armas. En una escena bélica del escudo de Aquiles (descrito en el libro XVIII), al igual que en IV 439, hallamos a los dos dioses guerreros, Ares y Atenea, conduciendo cada cual a un bando (516). También en la teomaquia Ares aúlla, como Atenea, dando órdenes a los troyanos (XX 51), y más adelante (358), los dos dioses se emparejan para enfrentarse entre sí. El desarrollo de la pelea entre ambos se describe en XXI 391-414. Ares insulta y reta a Palas Atenea, dándole un golpe en la égida. La diosa le da una pedrada en el cuello y lo pone fuera de combate. A continuación, se burla de él, aseverando que ella es mejor. Ares recuerda a la diosa el encuentro que, con Diomedes por medio, tuvieron en $\mathrm{V}$, y la diosa le repite que es un traidor, puesto que ha abandonado a los griegos y defiende a los troyanos. Cuando, herido por la diosa, Ares es sacado del combate por Afrodita (XXI 420-2; Afrodita es "auxiliar de Ares" -431-), Hera manda a Atenea que la ataque.

Para terminar con este dios en la Ilíada, conviene volver brevemente al libro V, donde Ares tiene mayor presencia. Recordemos que en V 31-4, Palas Atenea pide a Ares que los dioses (como ellos) abandonen el campo de batalla, recordándole la cólera de Zeus (34), que no desea que los dioses intervengan en el combate. Ahora bien, esa parte de su discurso es falsa, porque hasta VIII 5, ss., Zeus no ha dicho nada al respecto de la presencia o no de los dioses en los combates, antes al contrario, el mismo dios padre ha invitado a las dos divinidades pro-aqueas, Atenea y Hera, de que intervengan a favor de Menelao (IV 6 y 9-10). En cualquier caso, tras la propuesta de la diosa, Ares se retira, mientras que entran en acción Diomedes y demás dánaos (cf. V 36-7). Cabe preguntarse por el significado de esta contradicción: ¿se ha perdido algún pasaje (anterior al libro VIII) en que se especifica la cólera de Zeus por la intervención divina en los asuntos humanos? Hemos visto que la diosa Atenea aborda a Ares, sugiriéndole la no intervención, como acabamos de ver; mas, ¿qué ha hecho Ares al presente? Ella sin embargo, Atenea, a estas alturas del poema (en realidad, el primer poema, o Parisíada), ha engañado a Pándaro (libro IV), por lo que la 
diosa es doblemente cínica, ya que en V 33, para persuadir a Ares, le hace ver que acepta la decisión de Zeus sobre la victoria de unos u otros, siendo así que ella solo desea y espera que ganen los aqueos, de modo que el enfrentamiento divino (Ares, Palas Atenea y Afrodita) se plantea aquí ya, pero de una forma impresionista e ilógica (lo que en cierto modo caracteriza a la Ilíada): ¿cuestión de carácter o de una tradición escrita "sincopada", que ha perdido muchos eslabones?

\section{Afrodita}

"En Homero, Afrodita es la diosa de la belleza y el amor sensual" (Erbse 1986: 89). La primera mención de la diosa en la obra tiene lugar en función de su hijo, el héroe troyano Eneas: II 820 ("la divina Afrodita lo tuvo por obra de Anquises", referencia que se repite en V 313, y a la que alude Apolo, cuando conversa con Eneas, en XX 205; cf. también V 248 y XX 209). En el libro III, Hélena reprocha a su esposo troyano, Paris, los dones de Afrodita (54 y 64). Más adelante, la diosa del amor salva a Paris, y con aspecto de anciana habla a Hélena, quien, pese a su disfraz, descubre a la divinidad, contestando desabridamente a la diosa y negándose a ir con Paris al lecho, como le propone aquella. Afrodita, irritada, la amenaza con trocar su amor por ella (Hélena) en odio, y la mujer se rinde; ambas parten para la casa de la argiva. Esta protección de Afrodita a Paris es utilizada por Zeus para zaherir a Hera y Atenea (IV 10). Como ya sabemos, Afrodita es herida por Diomedes, a instancias de Atenea, en V 131-2. Más adelante, la diosa protege a su hijo Eneas, herido de una pedrada por Diomedes (V 311-429), cubriéndolo con sus brazos, y es a su vez herida por el guerrero argivo, instante en que la diosa, dolorida, abandona al hijo, que es ayudado por Apolo. Afrodita pide el carro a su hermano Ares, y con él sube al cielo, donde la cura y consuela su madre Dione. Zeus recuerda a la diosa que lo suyo es el amor, no la guerra. En IX 389, Afrodita aparece como símbolo de la belleza (los epítetos más usuales a ella asignados son "áurea" y "risueña"); en XIX 282, Briseida es comparada a ella, así como Casandra, en XXIII 699; en XXII 479, Andrómaca, al enterarse de la muerte de su esposo, Héctor, arroja al suelo el velo y cuantos regalos le había hecho Afrodita el día de su boda. Pese a que Hera odia a muerte a la diosa del amor, no tiene más remedio, como ya vimos, que recurrir a ella para que le procure un recurso erótico y poder así engatusar a Zeus. Hera, consciente de las malas relaciones entre las dos, toma sus precauciones (190-2): “¿Me harás caso, hija mía, o me denegarás el favor, irritada conmigo porque tú defiendes a los troyanos y yo a los dánaos?" También Afrodita es azotada por Atenea, que golpea a la diosa en el pecho y debilita sus rodillas y hace desfallecer su corazón (XXI 416-26). Finalmente, Afrodita protege de los perros el cadáver de Héctor, ungiendo su cuerpo con aceite inmortal, perfumado de rosas (XXIII 185-7). 


\section{HEFESTO}

"Es en origen pregriego, cario o tracio" (Erbse 1986: 76).

Para empezar, recordemos que Hefesto es el "dios del fuego", de ahí que simbolice este elemento en, por ejemplo, II 426, IX 468, XXIII 33.

Además, Hefesto es sobre todo "el herrero divino", que deja trazas de su arte a lo largo de la Ilíada. Así, en I 607-8, los dioses vuelven a la casa que a cada cual les ha fabricado Hefesto; como en XIV 166-7, Hera posee una alcoba construida por su hijo, y en XIV 338-9 se nos dice que el mismo ha construido la alcoba de Zeus; el cetro de Agamenón ha sido hecho por él (II 101-2), que primero se lo dio al Cronión y, luego, de divinidad en divinidad, vino a parar al "pastor de hombres"; asimismo, el dios del fuego fabrica la coraza de Diomedes (V 195); en XIV 238-41 construye igualmente un trono con escabel para Sueño, y en XV 309-10 conocemos que Hefesto le ha hecho la égida a Zeus, égida que ahora porta Apolo; para el mismo Zeus el "herrero divino" construye los pórticos de que es cuestión en XX 11-12.

Por supuesto, el dios del fuego aparece en la lista de dioses pro-aqueos (XV 214; XX 36 y 73-4). En calidad de tal, cuando Tetis le pide que fabrique unas armas para su hijo Aquiles, pues Héctor se ha quedado con las antiguas, "el ilustre artífice" (XVIII 137) le hará caso y procederá a fabricar la panoplia del héroe (XVIII 369-482). Tetis llega a la casa de Hefesto, que él mismo se ha construido (369-71). En ese momento, está haciendo veinte calderos con sus asas; Cárite, la esposa del herrero, recibe a la diosa marina; a continuación, Hefesto recuerda a su esposa cómo Tetis junto a Eurínoma lo ayudaron cuando Hera, su madre, lo envió lejos del Olimpo porque era cojo; por esa razón, el dios se muestra plenamente decidido a servir a Tetis. Hefesto se limpia la cara y las manos, el cuello y el pecho; se pone el chitón y coge el cetro, y en compañía de sus sirvientas robóticas sale al encuentro de la diosa del mar. Tetis cuenta al dios las desgracias de su hijo, Aquiles (429-461), y el dios le da ánimos, y promete hacerle unas espléndidas armas, que al momento se pone a fabricar con los veinte fuelles de que dispone (468-82); y lo primero que construye es el escudo de cinco láminas y muchos primores.

Ya dijimos que Hefesto aparece en la lista de dioses pro-aqueos. Por ello, en XX 36 se suma a la teomaquia, enfrentándose al río Janto (XX 70-3). En XXI 330-82, a petición de Hera, Hefesto combate al Janto, que, al sentirse abrasado, primero implora al dios (356-60) y acto seguido a su madre, Hera (369-76), quien finalmente permite a su hijo que cese de incendiar al río (379-80).

En la narración de su pasado, en el canto XVIII, Hefesto ha contado a su esposa, Cárite, que Hera, la madre, lo arrojó del Olimpo por ser cojo. En I 571-600, por el contrario, tras la riña de Zeus a Hera, el dios trata de consolar a su madre, a la que pide que se muestre sumisa a su esposo, y le cuenta que en una ocasión 
Zeus lo arrojó del divino umbral y, al cabo de un día, cayó en la isla de Lemnos, donde lo recogió el pueblo de los sinties. Por tanto, el padre lo tira desde el Olimpo, y el hijo se queda cojo; más tarde, la madre, Hera, lo echa fuera del cielo, porque el dios es cojo. ¡Bonita pareja la de los dioses supremos, Zeus y Hera, hermano y hermana, esposa y esposo!

\section{TETIS}

Tetis, hijo de Nereo, "el viejo de mar", es la madre de Aquiles, al que tuvo por obra de Peleo. El héroe confiesa a los embajadores, que en el canto IX acuden a su tienda para pedirle que reconsidere su postura de abandono de la lucha, que su madre le ha revelado que si se queda en Ilion, su vida será breve, pero su gloria inmarcesible; si por el contrario regresa a su patria, su vida será larga, aunque sin gloria (410-16); igualmente, en el canto XVIII, cuando Tetis sale al encuentro de su hijo, cuyos lamentos oye desde el fondo del mar, aquel le hace saber a la madre que no descansará hasta dar muerte a Héctor; la madre, entonces, le responde que, en ese caso, va a vivir poco, puesto que, tan pronto como muera el héroe troyano, caerá el propio Aquiles (95-6).

En I 350-427, Aquiles, mirando al mar, reza a su madre, Tetis, tras entregar a Briseida a los dos emisarios de Agamenón; en esa conversación, Tetis se compromete a hablar con Zeus para que, en compensación por la renuncia a Briseida, defienda a los troyanos y castigue a los aqueos. A la vuelta del dios supremo del país de los etíopes (495-528), Tetis visita a Zeus, al que solicita el castigo en cuestión a los griegos. El dios padre accede, y Tetis regresa al mar. Zeus, que, a cuenta de la promesa hecha a Tetis, ha tenido una grave discusión con su esposa, se lo recuerda a esta, varios cantos más adelante (XV 75-7), y el propio poeta nos recuerda que Zeus "quería darle la gloria a Héctor y cumplir con el desmesurado ruego de Tetis" (XV 598-9).

Enterado de la muerte de su amigo Patroclo, Aquiles se lamenta a voz en cuello (XVIII 35-148). Tetis, su madre, oye sus lamentos. Entonces, decide salir del mar "para ver a su querido hijo". Junto a las demás nereidas, suben a Troya, donde se hallan los mirmídones y Aquiles. Cogiendo la cabeza de su hijo, Tetis le pregunta el motivo de su llanto, que ella no comprende, puesto que Zeus ha hecho lo que ella le había pedido. El héroe contesta que ello no le da ninguna satisfacción, dado que ha muerto su mejor amigo. A la profecía de que, tras Héctor, morirá el propio Aquiles, este replica que no le importa morir, pues "la cólera fluye más dulce que la miel en el pecho de los hombres" (XVIII 109-10). Tetis le avisa de que encargará unas armas a Hefesto, y él, Aquiles, debe aguardar a que se las traiga. La diosa llega a la fragua de Hefesto y le pide las armas (cf. supra, XVIII 369-468, lo dicho sobre este pasaje a propósito del dios de la fragua). Tetis vuelve con las armas (XIX 3-39) y se las entrega a su hijo, que continúa llorando. 
Aquiles promete revestirse con ellas, pero antes pide a su madre que impida que el cadáver de Patroclo se agusane. La diosa vierte ambrosía y néctar por la nariz del muerto, y da fuerzas a su hijo. En XX 14, Tetis acompaña todavía las lamentaciones de su hijo por Patroclo. En XXIV Zeus pide que llamen a Tetis a su presencia; quiere encargarle que convenza a Aquiles para que devuelva el cadáver de Héctor. Iris busca a la diosa (83-142); Tetis marcha al Olimpo con ella; el dios padre le expone la situación y le pide que hable con su hijo; Tetis así lo hace; Aquiles acepta el plan de rescate.

\section{IRIS}

"Iris no aparece en la Odisea. Comporta las dos ideas de velocidad y de voz poderosa" (Erbse 1986: 11).

Como es sabido, Iris es la diosa mensajera de los dioses, y en especial, en la Ilíada, de Zeus. En calidad de tal, casi toda su actividad consiste en llevar a cabo misiones que le encarga el dios supremo. Por ejemplo, en II 786-806, donde, bajo la figura de Polites, hijo de Príamo, visita a este y a Héctor para exhortarles a que se preparen para el combate. De igual modo, en III 121-138, bajo la apariencia de Laódica, avisa a Hélena de la pelea entre Paris y Menelao; en V 353-5, realiza otro tipo de actividad: saca fuera del combate a Afrodita herida, para luego, montada en el carro de Ares, fustigar a los caballos y transportar a Afrodita ante su madre en el Olimpo (V 365-9). Llegadas al mismo, Iris desunce las bestias y les echa pienso. En VIII 398-425, Iris, por orden de Zeus, se encarga de frenar a Hera y Palas Atenea, a las que transmite, literalmente, la encomienda, añadiendo de su propia cosecha (cosa insólita) dos versos (423-4) en que amenaza a Hera, tras insultarla, si se atreve a "levantar su descomunal lanza contra Zeus". En XI 185210, por orden, otra vez, de Zeus, comunica a Héctor que se abstenga de combatir hasta que se retire Agamenón. En XV 55 Zeus encarga a Hera que llame a Iris y en 144-217 Hera le da el encargo a la diosa mensajera de que debe comunicar a Posidón que ha de abandonar el campo de batalla. Posidón, irritado, se resiste, e Iris, de nuevo, añade algún comentario por su cuenta y riesgo (201-2), que amedrenta al dios del mar, por lo que este cede de inmediato. En XVIII 166-202, por orden ahora de Hera, y a escondidas de Zeus y demás dioses, Iris se presenta ante Aquiles y le pide que se haga ver delante del foso para que los troyanos abandonen el cadáver de Patroclo. Acto seguido (202) "tras hablar así, se marchó Iris, de rápidos pies”. En XXIII 198-211, sin que lo pida Aquiles, Iris, por sí misma, ruega a los vientos Bóreas y Céfiro que acudan a encender la pira de Patroclo, porque el héroe les hará "un hermoso sacrificio". En XXIV 74-92, Iris comunica a Tetis que ha de acudir a presencia de Zeus; luego (95-99) la conduce ante el dios supremo; este revela a Tetis que va a enviar también a Iris ante Príamo, cosa que efectúa en versos 143-88, diciéndole que vaya a rescatar a Héctor. "Y así hablando, se marchó Iris, de pies rápidos” (188). 


\section{HERMES}

"Hermes acompaña a Príamo en XXIV 362-439 donde aparece joven. Esa relación divinidad-hombre se repite en la Odisea, en que Hermes acompaña a Ulises ante Circe (modelado según el Hermes iliádico, de acuerdo con Reinhardt" (Erbse 1986: 66).

La mayor presencia de Hermes es en el libro XXIV de la obra, un libro, por cierto, con acusadas reminiscencias odiseicas. Allí (333-469), Hermes, por orden de Zeus (también Hermes es un dios mensajero), acompaña a Príamo hasta la tienda de Aquiles, cuya puerta abre por arte de birlibirloque. En ese momento, se manifiesta como dios, hijo de Zeus, a Príamo y al viejo Ideo, y se vuelve al Olimpo. Más adelante, después de que Príamo ha cumplido su misión y recuperado el cadáver de su hijo, Hermes regresa (679-94) para sacar a Príamo del campamento de los griegos, al que acompaña hasta el cauce del Janto (o Escamandro). A continuación, parte definitivamente hacia el Olimpo.

Fuera de ese libro, es escasa la presencia del dios mensajero en el poema. Participa también en la teomaquia (XX 34-5), donde se enfrenta a Letó (madre de Apolo y de Ártemis; 72). Como de tantos otros dioses, de él se narra también alguna aventura amorosa, como que es el padre de Eudoro, que comandaba una flota de diez barcos, de los cincuenta que llegaron a Troya al mando supremo de Aquiles. Pues bien, Hermes se enamora perdidamente de Polimela, con la que yace en el ático de su casa, y de esa pasión nace Eudoro (XVI 181-86). Curiosamente, en V 390, el dios salva a Ares; y en II 104-5, nos enteramos de que el cetro de Agamenón ha pasado a manos de Hermes y este se lo da a Pélope, Pélope a Atreo, Atreo a Tiestes, y este, por fin, a Agamenón.

En conclusión, podemos decir que los dioses que pueblan la Ilíada de Homero tienen su origen, como los dioses de todos los pueblos antiguos, en el Oriente mesopotámico y la India, como zona indoeuropea, por un lado, y en Egipto y el Oriente Próximo, de raza y lengua semíticas, por el otro (no olvidemos que tres de las más importantes religiones de nuestro mundo, hermanas entre sí, que, en conjunto, agrupan el mayor número de creyentes de la Tierra, a saber, la judía, la cristiana y la musulmana, dimanan de la misma fuente semítica). Los dioses homéricos, lógicamente, fruto, como todo lo divino, de la mente humana, representan al mismo tiempo lo irracional y lo racional, de ahí que en el poema los simples mortales, juguete con frecuencia de las decisiones divinas, respondan, en sus actuaciones, a una "doble motivación" o "doble causa", como señalan Heubeck y Dalby, por ejemplo, de tal forma que esa creencia helénica de que "el hombre es la medida de todas las cosas" sea más que nada un desiderátum, pues el hombre antiguo, al igual, en cierta medida, que el moderno, dependa tanto de su creencia en la razón como de sus temores y dudas, que entre nosotros se expresan con el habitual recurso a la "providencia divina", y que emergen, incluso en los no creyentes, con frases comunes y triviales, como "si Dios quiere", "gracias a Dios", "Dios mediante", etc. 
También el ámbito de los héroes homéricos se plantea la debatida cuestión de la responsabilidad del hombre: ¿es este responsable de sus actos o mera marioneta de los dioses, como sugería Platón? Clara queda, sin embargo, la oposición entre los dioses inmortales y la mortalidad (y por tanto el carácter efímero) de la vida del hombre, que en más de un pasaje queda expresada por los personajes del poema (y que el mismo Zeus manifiesta, hablando a los caballos inmortales de Aquiles, por contraposición al ser humano, el más desgraciado, a juicio del dios supremo, de cuantos seres habitan la tierra).

Queda también patente en el estudio el incipiente rasgo ético de la máxima divinidad, Zeus, quien en la Odisea se convertirá en el dios justiciero que servirá de espejo a la sociedad de los hombres. Él, Zeus, se mantiene en la Ilíada, en todo caso, como árbitro supremo entre los hombres así como entre los dioses, debatiéndose olímpicamente entre los excesos de las demás deidades, las cuales, como los caprichosos mortales, se dejan llevar de idénticos impulsos y pasiones: Hera, que representa el odio y la perfidia; Palas Atenea, que representa la guerra, aunque también las labores artesanales, pero que vive del despecho y de los celos; Apolo, vengativo hacia los enemigos y bondadoso con los suyos, en especial Héctor, Eneas, Sarpedón y Glauco; Ares, el bruto y ciego dios de la guerra, y Afrodita, la dulce diosa del amor, que, no obstante, es capaz de adoptar una actitud violenta y agresiva, cuando alguien, como Hélena, se opone a sus dictados, y que, pese a todo, cae también en brazos del lerdo dios tracio, Ares, como la fábula de la Odisea pone de manifiesto."

\section{BiBLIOGRAFÍA}

Clarke 2004: M. Clarke, "Manhood and heroism", The Cambridge Companion to Homer (Cambridge 2004) 74-90.

Dalby 2008: A. Dalby, La reinvención de Homero (Madrid 2008).

Erbse 1986: H. Erbse, Untersuchungen zur Funktion der Götter im homerischen Epos (Berlin-New York 1986).

Heubeck 1974: A. Heubeck, Die Homerische Frage (Berlin 1974).

Janko 1992: R. Janko, The Iliad: a commentary (Cambridge 1992).

Kearns 2004: E. Kearns, "The Gods in the Homeric Epics", The Cambridge Companion to Homer (Cambridge 2004) 59-73.

Kirk 1985 y 1990: G. S. Kirk, The Iliad: a commentary (Cambridge 1985 y 1990).

Kullmann 1992: W. Kullmann, Homerische Motive (Stuttgart 1992).

Penglase 1994: Ch. Penglase, Greek Myths and Mesopotamia (London-New York 1994).

West 2003: M. L. West, The East Face of Helicon: West Asiatic Elements in Greek Poetry and Myth (Oxford 2003 [1997]).

West 2007: M. L. West, Indo-European Poetry and Myth (Oxford 2007). 